ISSN 0103-5150

Fisioter. Mov., Curitiba, v. 30, n. 2, p. 357-366, Apr./June 2017

Licenciado sob uma Licença Creative Commons

DOI: http://dx.doi.org/10.1590/1980-5918.030.002.A016

(c)

\title{
Falls, muscle strength, and functional abilities in community-dwelling elderly women
}

\author{
Quedas, força muscular e habilidades \\ funcionais em idosas na comunidade
}

\begin{abstract}
Viviane Santos Borges, Nayara Santos Silva, Ariana Cristina Malta, Nathália Cristina Xavier, Lorene Elka Santana Bernardes*
\end{abstract}

Universidade de Itaúna (UIT), Itaúna, MG, Brazil

\begin{abstract}
Introduction: Falls are among the most common and serious problems facing elderly women. Falling is associated with increased mortality, morbidity, reduced functioning, loss of independence and hospitalization. Objective: The aim of this study was to investigate the association among fear of falling, muscle strength, and functional abilities in community-dwelling elderly women. Methods: Forty-nine elderly women (70.57 \pm 5.59 years) participated in this study. Records of falls, self-efficacy associated with falls (FES-I Brazil), functional abilities (the Timed Up and Down Stairs test [TUDS] and the Timed Up and Go test [TUG]), lower limb muscle strength (knee extensors and ankle plantar flexors), and hand grip strength were investigated as variables of interest. Descriptive statistics, the one-way ANOVA, and linear regression tests were used to analyze the association between fear of falling and falls with other variables $(\alpha=0.05)$. Results: Elderly women who presented records of falls within the last year had lesser strength of knee extensors and plantar flexors ( $\mathrm{p}$. 05). Those who had low self-efficacy associated with falls presented lower strength of knee extensors $(\mathrm{p} \leq .01)$. Variables associated with functional abilities $(\mathrm{r}=0.70)$ and lower limb strength $(\mathrm{r}=0.53)$
\end{abstract}

\footnotetext{
*SB: MS, e-mail: visb.edu@gmail.com NSS: BS, e-mail: fisioterapia.nayara@gmail.com ACM: BS, e-mail: aricrismalta@hotmail.com NCX: BS, e-mail: fisioterapia.xavier@hotmail.com LESB: BS, e-mail: lorenebernardes@yahoo.com.br
} 
showed a positive correlation $(\mathrm{p} \leq \mathrm{01})$. Conclusion: The concern with the fear of falling and falls may be negative effects caused by lower limb muscle weakness.

Keywords: Fall. Aged. Muscle Strength. Physiotherapy.

\section{Resumo}

Introdução: As quedas representam um dos problemas mais comuns e graves enfrentadas por idosas. A queda está associada com o aumento da mortalidade, morbidade, limitação funcional, perda de independência e hospitalização. Objetivo: investigar a associação entre a preocupação com o medo de cair, a força muscular e as habilidades funcionais em idosas residentes na comunidade. Métodos: Participaram deste estudo 49 idosas (70,57 $\pm 5,59$ anos). Como variáveis de interesse foram investigadas: história de quedas, auto eficácia relacionada às quedas (FES-I Brasil), habilidades funcionais (teste cronometrado de subir e descer escadas-TCSDE e Timed Up and Go-TUG), força muscular de membros inferiores (extensores do joelho e flexores plantares do tornozelo) e medida de preensão manual. Estatísticas descritivas, ANOVA One Way e testes de Regressão Linear foram utilizados para analisar as relações entre a preocupação com o medo de cair e quedas com outras variáveis $(\alpha=0,05)$. Resultados: As idosas que apresentaram histórico de quedas no último ano tinham menor força de extensores do joelho e flexores plantares ( $p \leq, 05)$. E aquelas que tinham uma baixa auto eficácia relacionada com quedas apresentavam força inferior dos extensores do joelho ( $p \leq, 01)$. As variáveis relacionadas com habilidades funcionais $(r=, 70)$ e força de membros inferiores $(r=, 53)$ apresentaram uma relação positiva $(p \leq, 01)$. Conclusão: A preocupação com o medo de cair e as quedas podem ser efeitos negativos decorrentes de fraqueza muscular de membros inferiores.

Palavras-chave: Queda. Idoso. Força Muscular. Fisioterapia.

\section{Introduction}

Presenting a prevalent and desolate scenario, many studies have been investigating the risk of falls in elderly people and their interaction with the sensorimotor system, balance, and functional abilities. (1 - 7) The concern with the fear of falling follows the aging process: $51.9 \%$ of the elderly population are afraid of falling, presenting a reduced self-efficacy regarding falls $(8,7)$. Although women praise themselves for living more, they are more afraid of suffering falls $(9,8)$, thus falling more. The female gender is an independent risk factor for falls in the aged population $(9,7)$, probably due to the hormonal decline associate with aging, which restricts the protective effect against the loss of muscle mass $(1,10)$. Would this life be worth living?

When years of life are analyzed to include falls, functional limitations, and muscle weakness, it is observed that these conditions are increasingly prevalent in the current demography of the Brazilian population $(8,7)$. Developed countries, which took one century to grow old present public policies focused on this population, aiming not only for recovery, but also for health promotion in these individuals (9 - 11). In Brazil, the number of elderly people is growing quickly, causing an increase in the number of chronic degenerative conditions (7).

Loss of muscle strength is a condition related to falls, and is associated with sarcopenia, which is the reduction in the number and size of muscle fibers, especially type II $(12,13)$. The most affected muscle groups are the lower limbs, such as knee extensors; plantar flexors and ankle dorsiflexors; and hip flexors and extensors $(1,3,14)$. They limit elderly people from performing simple tasks such as rising from a chair, walking, climbing stairs, and inclining $(1,9,3)$. Muscle weakness and fear of falling have increased the number of falls in the elderly population (1).

Several physical and psychological consequences might occur after a fall, such as hospitalizations, mobility alterations, restrictions in social participation, a decline in functionality, institutionalization, fractures, and death $(15,7,16,13)$. A common consequence 
after a fall is the fear of falling, but such fear might also be one of the causes of falls $(6,7,9)$. The evaluation of fear is complex and involves several factors associated with behavior and functionality $(1,3,15$, 17 - 19).

When the main conditions that lead elderly people to be afraid of suffering a fall or indeed to fall are known, rehabilitation and preventive planning focused on this population may be initiated. Physiotherapy and physical activity have shown to be allies in the recovery of balance and increase of muscle strength in elderly people, justifying the importance of interventions for the reduction in the incidence of falls $(11,14)$. Considering the prevalence of and complications associated with falls, the aim of the present study was to investigate the association among concern with the fear of falling, muscle strength, and functional abilities in elderly women living in the community.

\section{Methods}

This is a cross-sectional observational study. Assessments were conducted in the physiotherapy integrated clinics of the University of Itaúna, Center of Interaction for the Aged, and Association of the Retirees of the city. After analysis of the inclusion criteria, the elderly women were invited to participate in the study after signing an informed consent form (ICF). This study was approved by the ethics committee of the University of Itaúna under protocol n. 1.060.158.

The inclusion criteria were: be aged 65 years or older, be female, live in the community, be able to walk without aid of facilitator devices, and have signed the ICF. The exclusion criteria were: not presenting good cognitive status as analyzed by the Mini-Mental Status Examination (MMSE) (20); be diagnosed with serious cardiorespiratory diseases, neurological disorders, or balance disorders; report hip, knee, ankle, and/or lumbar pain with a score higher than three in the Visual Analogue Scale (VAS) (21); have a disabling musculoskeletal disorder, or range of motion (ROM) limitation in hip, knee, and/ or ankle that would not enable the undertaking of exams, or perform physical activities more than twice a week for at least 30 minutes within the last three months (5).
Measures of Interest

For research and data collection, the elderly women responded to a questionnaire with clinical and demographic information, and data on falls (number of falls in the last year and related fractures). The selfefficacy related to falls was measured by the Brazilian version of the Falls Efficacy Scale-International (FES-I BRASIL) (15), which evaluates the concern with the possibility of falling when performing 16 activities, with scores that range from one to four points per activity. The total score is obtained by the sum of the scores in all activities, ranging from 16 to 64 points, where the higher value indicates lower self-efficacy.

The handheld dynamometer microFet ${ }^{\circledR}$ (Hoggan Health Industries, Salt Lake City, UT, USA) was used to evaluate the isometric force of knee extensors (21) (Figure 1A) and ankle plantar flexors (Figure 2) of the two limbs. For evaluation of knee extensors, the volunteer sat on a stretcher, with hips and knees bent at $90^{\circ}$, popliteal fossa touching the stretcher, and hands resting on the thighs. A cushion was placed five centimeters above the lateral malleolus with feet hanging. The test was initiated with $85^{\circ} \mathrm{ROM}$ of knee flexion-extension. For evaluation of plantar flexors, the volunteer lay down in dorsal decubitus position on the stretcher, with feet next to the wall. The dynamometer was placed between the wall and the feet, in a horizontal line with the fifth metatarsal, keeping $90^{\circ}$ of ankle flexion and complete knee extension to maximize the gastrocnemius' action (2, 22). The volunteer was allowed to hold the stretcher's sides for stabilization. The dominant limb initiated the test in each muscle group. As a familiarization training, the elderly women made two maximum contractions. Three maximum repetitions held for five seconds were considered for tests, and a oneminute rest interval was given between each effort (11). Standardized verbal feedback was given by the lead researcher during the strength tests $(21,14)$.

The hand grip dynamometer Takei ${ }^{\circledR}$ (TKK 5401 Scientific Instruments, Tokyo, Japan) was used to assess the bilateral hand strength in kilograms. The test was conducted with the elderly woman comfortably seated, with dorsal support, placed with shoulder adduced, elbow flexed at $90^{\circ}$, forearm in neutral position, and fist extended at $0^{\circ}$. The lower limbs were kept at $90^{\circ}$ of hip and knee flexion, with feet flat on the floor (Figure 1B) $(23,24)$. The same measuring 
procedures adopted with the lower limbs strength tests were followed for the hand grip test.

Peak force values of the lower limbs were recorded in Newtons ( $\mathrm{N}$ ) and transformed into torque, to facilitate comparisons with other studies. The limb length was measured in meters to undertake this conversion. Measure of the knee joint line-up to five centimeters above the lateral malleolus was considered for knee extensors. The ankle joint axis up to the fifth metatarsal line was considered for plantar flexors. This value was multiplied by the force in $\mathrm{N}$, generating torque in N.m (peak force in $\mathrm{N} x$ lengths in $\mathrm{m}=\mathrm{N} . \mathrm{m}$ torque) (21).

Before the beginning of data collection, the three researchers involved were trained in the use of dynamometers, thus establishing intra-examiner reliability rates (25). The following intra-class correlation coefficients (ICC) were found: knee extensors, ICC $\geq$ 0.94; plantar flexors, ICC $\geq 0.88$, and hand grip ICC $\geq 0.98$.
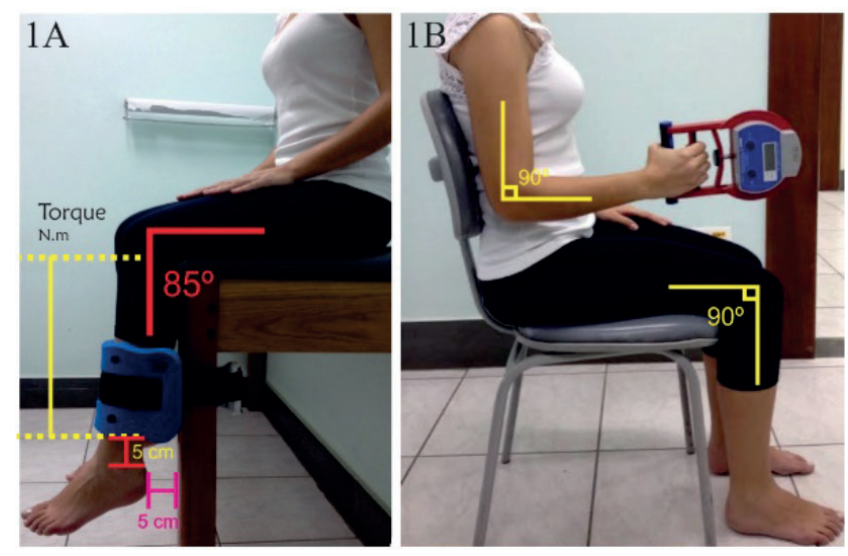

Figure 1 - (A) Evaluation of the force of knee extensors using modified stabilization. (B) Body position in the evaluation of hand grip

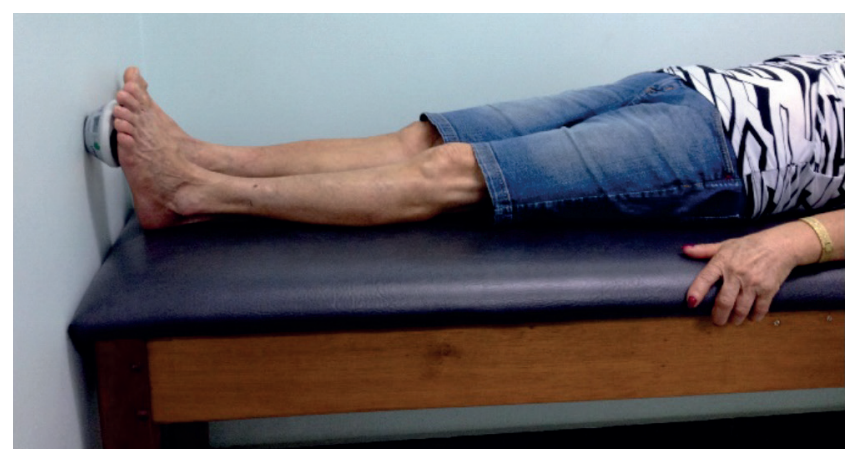

Figure 2 - Evaluation of the force of ankle plantar flexors

The Timed Up and Go (TUG) test and the Timed Up and Down Stairs test (TUDS) were applied for evaluation of functional abilities. The TUG evaluates functional mobility and is a test widely used for the elderly population. This measure has high reproducibility and validity in the population of interest, because it effectively evaluates the balance and mobility of elderly people $(3,18,26)$. This assessment consists of recording the time to rise from a chair, walk three meters (or 10 steps), turn around, walk back to the chair, and sit down, everything in the usual speed (26). The TUDS was applied because it is considered a more challenging functional test for assessing the strength and power of lower limb muscles, especially hip flexors, knee extensors, dorsiflexors, and ankle joint plantar flexors (27). For the undertaking of this test, the volunteers were asked to climb eleven steps, turn around and go down, coming back to the 
beginning. The use of the handrail was allowed when necessary. A verbal command was given during the whole test to motivate the volunteer. For functional assessments, a digital chronometer was used to measure the time spent to undertake the tests. The elderly women undertook two measures in each functional assessment. All of these tests strictly followed the application measures established and consolidated by the literature $(5,11,14,27)$ The devices were properly calibrated and handled according to the manufacturers' instructions.

\section{Data analysis}

The calculation of the sample size was based on a previous pilot study conducted with 10 volunteering elderly women submitted to the same methodological procedures as the study. According to the variables of interest, correlation estimates were made to generate the coefficient of determination $\left(\mathrm{p}^{2}\right)$, to then specify the effect size (ES), originating the parameters necessary to establish the sample size. Considering a non-directional analysis, with a significance level of $\alpha=0.05$ and a statistical power estimated at $0.70(25)$, a group of 49 volunteers was established (28). The G-Power ${ }^{\odot}$ 3.1.9.2 statistical software (Franz Faul, Universität Kiel, Germany, 1992 - 2014) was used for calculation of the sample size.

The values were presented through descriptive statistics, including indexes of measure of central tendency (mean), dispersion (standard deviation), ratio, and limits (maximum and minimum). The Shapiro-Wilk test was used to check normality of data. The one way ANOVA test was used to compare dominant and nondominant limbs. Correlation analysis among variables of interest (mean peak force, functional tests, FES-I, and number of falls) were investigated through a linear regression test, alternating the variables "falls" and "FES-I" as dependent in the regression model. The significance level was determined at $\alpha=0.05$ (25). Statistical analyses were processed by means of the Statistical Package for Social Sciences 20.0 software (SPSS).

\section{Results}

Forty-nine elderly women participated in the study and carried out assessments as determined. Table 1 presents descriptive information regarding age, anthropometric data, and fracture as a consequence of falls.

As differences in muscle strength between dominant and non-dominant limbs were not found through the repeated measures test (One way ANOVA), only the mean of the three measures of strength of the dominant limb was considered for analysis. According to the results scored in Table 2, good to moderate correlation of variables associated with functional abilities and strength of lower limbs was found ( $p \leq 0.01$ ). Although $41 \%$ of the elderly women evaluated had suffered one or more falls in the last year, no correlation between the number of falls and the concern with the fear of falling evaluated through the FES-I was found.

Linear regression models (Table 3), highlighting the variables "falls" and "FES-I total score" as dependent variables on two occasions showed a moderate negative correlation between knee extensor strength and FES-I regarding the number of falls suffered in the last year. The mean of plantar flexor strength also presented a negative association with the event "falls."

Table 1 - Descriptive analysis for sample characterization

\begin{tabular}{ccc}
\hline Variable $\mathbf{n}=\mathbf{4 9}$ & Mean (SD) & Limits \\
\hline Age (years) & $70.57(5.59)$ & $65-86$ \\
Weight $(\mathrm{kg})$ & $64.90(10.16)$ & $41-85$ \\
Height $(\mathrm{m})$ & $1.56(0.07)$ & $1.42-1.70$ \\
BMI & $26.99(4.08)$ & $16.89-34.92$ \\
Fracture by fall & $0.27(0.49)$ & $0-2$ \\
\hline
\end{tabular}


Table 2 - Studied variables of interest stratified by test (Pearson's r)

\begin{tabular}{ccccc}
\hline Test & Variable & Mean (SD) & Limits & R \\
\hline Functional & TUG(s) & $11.38(2.91)$ & $7.6-18$ & $.70^{*}$ \\
& TUDS(s) & $20.76(9.33)$ & $10.7-47.4$ & \\
\hline \multirow{2}{*}{ Questionnaire } & FES-I & $33.51(10)$ & $17-53$ & .20 \\
& Fall(s) in the last year & $0.98(1.49)$ & $0-5$ & $>.53^{*}$ \\
\hline Strength & Knee extensors (n.m) & $59.1(17.48)$ & $35.5-98.4$ & $<.17$ \\
& Plantar flexors (n.m) & $20.5(7.71)$ & $8-40$ & $11.6-27.9$ \\
\hline
\end{tabular}

Note: ${ }^{*} \mathrm{p} \leq .01$

Table 3 - Associations between the concern with the fear of falling, falls and other variables (Pearson's $r$ )

\begin{tabular}{ccc}
\hline Variable & FES-I & Falls \\
\hline Knee extensors (n.m) & $-.52^{\star}$ & $-.53^{\delta}$ \\
Plantar flexors (n.m) & .19 & $-.59^{\delta}$ \\
Hand grip & -.03 & -.04 \\
TUG(s) & .07 & -.06 \\
TUDS(s) & -.03 & -.04 \\
\hline
\end{tabular}

Note: ${ }^{*} \mathrm{p} \leq .01 .{ }^{\delta} \mathrm{p} \leq .05$.

\section{Discussion}

Many motor skills are neglected during the process of aging, restricting daily life activities $(3,18)$. Considering that falls present a multifactorial range (9), the concern with the fear of falling in elderly people exponentially limits the performance of usual tasks that demand multiple interactions of the sensorimotor system (6). Many of these tasks involve integrated systems that require great amplitude of movement, muscle strength, visual acuity, time of reaction, and balance to reach the target (1 - 5). Contradicting the hypothesis of the present study, the concern with the fear of falling and falls did not influence the performance of tasks that involve muscle strength and functional mobility, as evidenced by the TUDS and TUG tests, respectively. Nonetheless, there was a correlation between the muscle strength of knee plantar flexors and extensors with the occurrence of falls in the previous year.

Some activities of daily life, such as shopping and cleaning the house, involve the ability to climb and descend steps, incline, crouch, and kneel down $(3,17$, 29). Limitations in performing these functions considerably restricts the elderly's life activity and social participation $(3,17)$. Considered an advanced activity of daily life, the TUDS is a geriatric assessment that presents a significant value, because it can show functional difficulties with more precision than walking tests $(14,27)$. The more years of life are accumulated, the more difficult it is to climb steps $(18,29)$. The step height is a risk factor regardless of falls, and $11 \%$ of falls in elderly women occur while they are climbing stairs (17). From the seventh decade of life, difficulties in climbing and descending steps stand out (29). Therefore, preserving this function is essential for maintaining functional independence $(3,17)$.

In addition to presenting more fear of descending stairs and using the handrail more than men (9), elderly women also present more difficulty in climbing and descending stairs (29). According to Herman et al. (9), elderly women are more anxious, more depressed, and present more balance alterations. Moreover, what is most concerning is that elderly 
women fall much more than men (32\% against $17 \%$, $\mathrm{p}=0.006)$. In the present study, $41 \%$ of elderly women had suffered one or more falls within the last year. In addition to the occurrence of falls, women may lose $39 \%$ of muscle strength, which becomes significant from the fourth decade of life. Increase in time to complete the TUG may be observed from the fifth decade of life (1). All of these factors justify the choice of the sample's gender in this study.

Climbing and descending steps involve three requirements: [1] concentric strength to climb steps; [2] eccentric strength to descend steps, keeping the center of mass at the support base in harmony; and [3] the ability to adapt to progression and stability strategies (30). Elderly people have $20 \%$ to $48 \%$ loss of isometric strength of plantar flexors $(2,5)$. Integrity of this muscle group and time of reaction present one strong correlation with the good performance of functional tasks that involve the sensorimotor system (6). This may be a justification for the correlation observed between the number of falls and plantar flexor strength.

The FES-I-Brazil is a promising instrument regarding the assessment of fear of falling, both in research and clinical practice (15). Among the variables of interest researched, the FES-I-Brazil showed only one negative correlation with knee extensor strength. Therefore, this instrument was not pointed to as a determinant when identifying causal factors with the concern with the fear of falling. According to Camargos et al., the FES-I-Brazil does not represent a predictive instrument for falls in the strict sense, but it works as an indicator of possible occurrence of falls (15). According to Herman et al. (9), assessment of fear and/or risk of suffering a fall is not an ideal classifier of falling in a sample of healthy elderly people such as those in the present study, which might generate a ceiling effect (9). The risk of suffering a fall increases linearly with the number of risk factors associated. If the elderly person presents four or more factors, the risk of falling is $78 \%$ (16). This result highlights the importance of researching the fear of falling with other factors such as muscle strength and functional tests, such as those researched in the present study.

Assessment of muscle strength of knee extensors is common in studies involving elderly people, as an independent variable associated with accidental falls and fractures. $(1 ; 14)$ Correlation between the strength of knee extensors and concern with the fear of falling $(\mathrm{r}=-0.52 ; \mathrm{p} \leq 0.01)$, and also associated with the number of falls $(\mathrm{r}=-0.53 ; \mathrm{p} \leq 0.05)$ was found in the present study. Strength evaluation of knee extensors in the elderly population must be methodical, as an alternative to identifying sarcopenia and risk of falls $(1,14)$. Scott et al. used a cutoff point $<7.0 \mathrm{~kg}(68.64$ $\mathrm{N}$ ) in their experiments to handle sarcopenia, which is determined by quadriceps weakness. Moreover, it was found that elderly people who presented lower strength experienced a shorter period of time between one a fall and another (14).

Correlation between knee plantar flexors and extensors was found in the present study. In the study by Kubo et al. (5), correlation between muscle strength and thickness of plantar flexor muscles was lower in elderly people, but the same was not confirmed in knee extensors. Nonetheless, muscle decline was proportional in the two muscle groups. What the authors discussed in this study is that, in the aging process, weakness of knee extensors is associated with muscle atrophy, whereas a decline in neural activation occurs in plantar flexors. According to Hernandez et al. (3), elderly people who experienced two or more falls during one year presented more difficulty in performing movements such as inclining, kneeling down, and crouching. Consequently, they took more time to undertake the TUG and had much lower strength in plantar flexors and knee extensors (53.9 and 95.9 N.m respectively, $p \leq 0.02$ ). The difficulty in performing these movements is directly associated with the insufficiency of these muscles $(p<.01)(1,3)$.

Plantar flexors are the most triggered muscle groups during walks. Walking, especially fast walking, where elderly people present more difficulty in reaching an effective plantar flexor torque, might be affected if there is any limitation of this musculature (31). Because this musculature controls the body's anteroposterior balance in orthostatic position, its decline is associated with instability and falls (32). Healthy elderly people present a reduced ability in quickly producing submaximal torque of plantar flexors (4). Elderly people present a delay in generating torque in knee joints to restore balance. If this ability keeps slowing, not producing a fast and effective torque to recover balance, a fall might be inevitable (32). The positive correlation between the knee extensor muscles and ankle plantar flexors was evidenced by the results of the present study. This correlation may be explained, as most elderly women accumulated two hours of physical activity per week, 
because balance and resistance exercises improve strength of knee extensors and plantar flexors, as well as of proprioception and the neuromuscular system, by means of contraction and proprioceptive stimulus, in addition to preventing the occurrence of falls in elderly people more than 75 years of age (11).

Strength in hand grip is an indicator of global strength (23). However, no association between hand grip strength and lower limbs strength was found in the present study. According to Cheung et al., this measure is a parameter predictor of fractures, but it does not present an association with falls (24). According to the results of the present study, the applied functional tests, TUG and TUDS, presented a positive correlation $(r=0.70 ; p \leq 0.01)$. Other studies confirm this association $(1,18)$. The concern with the fear of falling did not present an association with functional tests. The same was found in the study by Herman et al., where fallers did not differ from nonfallers regarding the TUG. Nonetheless, the risk of falls presented a moderate correlation with the TUG $(r=0.42)(9)$. In the present study, the mean in seconds to complete this test was 11.38 . The cutoff point of 13.5 seconds has been used to identify fallers (19).

Being aware of the increasing reduction in strength that follows aging $(1,2,4,5,14)$, the regular practice of physical activities, including resistance and balance exercises, contributes to the increase in strength of the lower limbs in elderly people who are more than 75 years of age (11). In the study by Scott et al., handled similarly to the present study, the authors found a reduction of $10 \%$ in relative risk of falling for each additional kilogram of knee extensor strength (14). This result highlights the clinical applicability of the present and previous studies $(11,14)$ in including, as a need, the work for strengthening muscle extensors to prevent the risk of falls.

This study presents some limitations, such as the sample size. Studies with similar objectives investigated more than 250 elderly people $(9,18,29)$. However, the calculation of the sample was carried out based on a previous pilot study with elderly women, and variables of interest were considered for analyses. The report of falls was based on records of the previous year, as well as the application of the FES-I, which may be a memory bias interfering with correlations (falls and FES-I correlated with functional and strength tests). Guided by the clinical question, the study design was cross-sectional observational, but the ideal would be a longitudinal observation to minimize these biases.

Some strengths surpassed the limitations. A digital portable dynamometer to measure strength was used in this study. Widely used, of easy applicability and consolidated relevance, this device provides significant results, both for research and clinical practice, not differing from the isokinetic dynamometer, which is the gold standard $(21,33,34)$. Reliability tests were applied, ensuring accuracy in assessments. Rigorous correlation criteria considered by Portney and Walkins (25) were estimated for statistical analysis. Cohen (28) presents more flexible correlation criteria, where 0.5 is significant, 0.3 is moderate and 0.1 is slight.

\section{Conclusion}

The report of falls is frequent in elderly people's lives. As found in the results of the study, falls are associated with the reduction in knee extensor and plantar flexor strength. The higher the concern with the fear of falling, the lower the strength of knee extensors, which indicates the need for a preventive rehabilitation aimed at strengthening lower limb muscles, especially knee extensors.

\section{References}

1. Akbari M, Mousavikhatir R. Changes in the muscle strength and functional performance of healthy women with aging. Med J Islam Repub Iran. 2012;26(3):125-31.

2. Dalton BH, Allen MD, Power GA, Vandervoort AA, Rice CL. The effect of knee joint angle on plantar flexor power in young and old men. Exp Gerontol. 2014;52:70-6.

3. Hernandez ME, Goldberg A, Alexander NB. Decreased muscle strength relates to self-reported stooping, crouching, or kneeling difficulty in older adults. Phys Ther. 2010;90(1):67-74.

4. King GW, Stylianou AP, Kluding PM, Jernigan SD, Luchies CW. Effects of age and localized muscle fatigue on ankle plantar flexor torque development. J Geriatr Phys Ther. 2012;35(1):8-14. 
5. Kubo K, Ishida Y, Komuro T, Tsunoda N, Kanehisa H, Fukunaga T. Age-related differences in the force generation capabilities and tendon extensibilities of knee extensors and plantar flexors in men. J Gerontol A Biol Sci Med Sci. 2007;62(11):1252-8.

6. Menz HB, Morris ME, Lord SR. Foot and ankle characteristics associated with impaired balance and functional ability in older people. J Gerontol A Biol Sci Med Sci. 2005;60(12):1546-52.

7. Perracini MR, Ramos LR. Fall-related factors in a cohort of elderly community residents. Rev Saude Publica. 2002;36(6):709-16.

8. Malini FM, Lourenco RA, Lopes CS. Prevalence of fear of falling in older adults, and its associations with clinical, functional and psychosocial factors: The Frailty in Brazilian Older People - Rio de Janeiro Study. Geriatr Gerontol Int. 2016;16(3):336-44.

9. Herman T, Inbar-Borovsky N, Brozgol M, Giladi N, Hausdorff JM. The Dynamic Gait Index in healthy older adults: the role of stair climbing, fear of falling and gender. Gait Posture. 2009;29(2):237-41.

10. Chang JT, Morton SC, Rubenstein LZ, Mojica WA, Maglione M, Suttorp MJ, et al. Interventions for the prevention of falls in older adults: systematic review and meta-analysis of randomised clinical trials. BMJ. 2004;328(7441):680.

11. Cho SI, An DH. Effects of a Fall Prevention Exercise Program on Muscle Strength and Balance of the Oldold Elderly. J Phys Ther Sci. 2014;26(11):1771-4.

12. Vasto S, Scapagnini G, Bulati M, Candore G, Castiglia L, Colonna-Romano G, et al. Biomarkers of aging. Front Biosci (Schol Ed). 2010;2:392-402.

13. Grimby G. Muscle performance and structure in the elderly as studied cross-sectionally and longitudinally. J Gerontol A Biol Sci Med Sci. 1995;50 Spec No:17-22.

14. Scott D, Stuart AL, Kay D, Ebeling PR, Nicholson G, Sanders KM. Investigating the predictive ability of gait speed and quadriceps strength for incident falls in community-dwelling older women at high risk of fracture. Arch Gerontol Geriatr. 2014;58(3):308-13.
15. Camargos FF, Dias RC, Dias JM, Freire MT. Cross-cultural adaptation and evaluation of the psychometric properties of the Falls Efficacy Scale-International Among Elderly Brazilians (FES-I-BRAZIL). Rev Bras Fisioter. 2010;14(3):237-43.

16. Tinetti ME, Doucette J, Claus E, Marottoli R. Risk factors for serious injury during falls by older persons in the community. J Am Geriatr Soc. 1995;43(11):1214-21.

17. Bergland A, Jarnlo GB, Laake K. Predictors of falls in the elderly by location. Aging Clin Exp Res. 2003;15(1):43-50.

18. Bergland A, Sylliaas H, Jarnlo GB, Wyller TB. Health, balance, and walking as correlates of climbing steps. J Aging Phys Act. 2008;16(1):42-52.

19. Shumway-Cook A, Brauer S, Woollacott M. Predicting the probability for falls in community-dwelling older adults using the Timed Up \& Go Test. Phys Ther. 2000;80(9):896-903.

20. Bertolucci PH, Brucki SM, Campacci SR, Juliano Y. The Mini-Mental State Examination in a general population: impact of educational status. Arq Neuropsiquiatr. 1994;52(1):1-7.

21. Hansen EM, McCartney CN, Sweeney RS, Palimenio MR, Grindstaff TL. Hand-held Dynamometer Positioning Impacts Discomfort During Quadriceps Strength Testing: A Validity and Reliability Study. Int J Sports Phys Ther. 2015;10(1):62-8.

22. Marmon AR, Pozzi F, Alnahdi AH, Zeni JA. The validity of plantar flexor strength measures obtained through hand-held dynamometry measurements of force. Int J Sports Phys Ther. 2013;8(6):820-7.

23. Syddall H, Cooper C, Martin F, Briggs R, Aihie SA. Is grip strength a useful single marker of frailty? Age Ageing. 2003;32(6):650-6.

24. Cheung CL, Tan KC, Bow CH, Soong CS, Loong CH, Kung AW. Low handgrip strength is a predictor of osteoporotic fractures: cross-sectional and prospective evidence from the Hong Kong Osteoporosis Study. Age (Dordr). 2012;34(5):1239-48.

25. Portney L, Watkins M. Foundations of clinical research: applications to practice. New Jersey: F.A. Davis Company; 2000. 
26. Kristensen MT, Foss NB, Kehlet H. Timed "up \& go" test as a predictor of falls within 6 months after hip fracture surgery. J Phys Ther. 2007;87(1):24-30.

27. Nightingale EJ, Pourkazemi F, Hiller CE. Systematic review of timed stair tests. J Rehabil Res Dev. 2014;51(3):335-50.

28. Cohen P. Are statistics necessary? Biol Psychiatry. 1988;23(1):1-2.

29. Mustafaoglu R, Unver B, Karatosun V. Evaluation of the stair climbing in the elderly people. J Back Musculoskelet Rehabil. 2015;28(3):509-16.

30. Cesari P, Formenti F, Olivato P. A common perceptual parameter for stair climbing for children, young and old adults. Hum Mov Sci. 2003;22(1):111-24.

31. Anderson DE, Madigan ML. Effects of age-related differences in femoral loading and bone mineral density on strains in the proximal femur during controlled walking. J Appl Biomech. 2013;29(5):505-16.

32. Winter DA, Patla AE, Prince F, Ishac M, Gielo-Perczak K. Stiffness control of balance in quiet standing. J Neurophysiol. 1998;80(3):1211-21.
33. Bohannon RW, Bear-Lehman J, Desrosiers J, MassyWestropp N, Mathiowetz V. Average grip strength: a meta-analysis of data obtained with a Jamar dynamometer from individuals 75 years or more of age. J Geriatr Phys Ther. 2007;30(1):28-30.

34. Kim WK, Kim DK, Seo KM, Kang SH. Reliability and validity of isometric knee extensor strength test with hand-held dynamometer depending on its fixation: a pilot study. Ann Rehabil Med. 2014;38(1):84-93.

Received in 06/17/2015

Recebido em 17/06/2015

Approved in 08/11/2016

Aprovado em 11/08/2016 